\title{
VEGFR-1 Regulates Adult Olfactory Bulb Neurogenesis and Migration of Neural Progenitors in the Rostral Migratory Stream In Vivo
}

\author{
Ina M. Wittko, ${ }^{1,2}$ Anne Schänzer, ${ }^{1}$ Andrey Kuzmichev, ${ }^{2}$ Fabian T. Schneider, ${ }^{1}$ Masabumi Shibuya, ${ }^{3}$ Sabine Raab, ${ }^{1 *}$ \\ and Karl H. Plate ${ }^{1 *}$ \\ ${ }^{1}$ Goethe University Medical School, Institute of Neurology (Edinger Institute), Neuroscience Center, 60528 Frankfurt am Main, Germany, ${ }^{2}$ Laboratory of \\ Molecular Biology, National Institute of Neurological Disorders and Stroke, Porter Neuroscience Research Center, National Institutes of Health, Bethesda, \\ Maryland 20892, and ${ }^{3}$ Department of Molecular Oncology, Tokyo Medical and Dental University, Bunkyo-ku, Tokyo 113-8519, Japan
}

The generation of new neurons in the olfactory bulb $(\mathrm{OB})$ persists into adulthood and is a multistep process that includes proliferation, fate choice, migration, survival, and differentiation. Neural precursor cells destined to form olfactory interneurons arise in the subventricular zone (SVZ) and migrate along the rostral migratory stream (RMS) to the OB. Recently, some factors classically known from their effects on the vascular system have been found to influence different steps of adult neurogenesis. In the present study, we report a modulatory function for the vascular endothelial growth factor receptor-1 (VEGFR-1) in adult olfactory neurogenesis. We identified expression of VEGFR-1 in GFAP-positive cells within regions involved in neurogenesis of the adult mouse brain. To determine functions for VEGFR-1 in adult neurogenesis, we compared neural progenitor cell proliferation, migration, and differentiation from wild-type and VEGFR-1 signaling-deficient mice (Flt-1TK ${ }^{-I-}$ mice). Our data show that VEGFR-1 signaling is involved in the regulation of proliferation of neuronal progenitor cells within the SVZ, migration along the RMS, and in neuronal differentiation and anatomical composition of interneuron subtypes within the OB. RMS migration in Flt-1TK ${ }^{-1-}$ mice was altered mainly as a result of increased levels of its ligand VEGF-A, which results in an increased phosphorylation of VEGFR-2 in neuronal progenitor cells within the SVZ and the RMS. This study reveals that proper RMS migration is dependent on endogenous VEGF-A protein.

\section{Introduction}

Neurogenesis in the adult mammalian brain is mainly confined to two regions: the subventricular zone (SVZ) of the lateral ventricles (LV) and the dentate gyrus of the hippocampus (HC) (Altman and Das, 1965; Cameron et al., 1993; Levison and Goldman, 1993; Luskin, 1993). The SVZ is the source of neuronal progenitor cells (NPCs), which migrate through the rostral migratory stream (RMS) to the olfactory bulb (OB), in which they differentiate into new functional olfactory neurons (Luskin, 1993; Carlén et al., 2002).

Generating new neurons is a multistep process that includes

\footnotetext{
Received Nov. 12, 2008; revised Feb. 27, 2009; accepted May 28, 2009.

This work was supported by the Deutsche Forschungsgemeinschaft (Project PL158/5-3, SPP 1109) and the German Israeli Foundation (GIFI-740). A.K. was supported by the Division of Intramural Research Program/National Institute of Neurological Disorders and Stroke-National Institutes of Health. We are grateful to R. D. G. McKay for support, valuable discussions, and laboratory space. We express thanks to H. Rohrer and V. Taylor for helpful discussions, to J. D. Boyd and S. Momma for critically reading this manuscript, and to A. Beckert, M. Damm, J. Drynski, and C. Schneider for excellent technical assistance. We thank G. Breier for the gift of the VEGFR-1 in situ hybridization CDNA probe.

Correspondence should be addressed to Karl H. Plate, Goethe University Medical School, Institute of Neurology (Edinger Institute), Neuroscience Center, Heinrich-Hoffmann Strasse 7, 60528 Frankfurt am Main, Germany. E-mail: karl-heinz.plate@kgu.de.

A. Schänzer's present address: Institute of Neuropathology, University Medical School Giessen Marburg, Arndtstrasse 16, 35392 Giessen, Germany.

S. Raab's present address: Merck Serono, Merck KGaA, Frankfurter Strasse 250, 64293 Darmstadt, Germany. D01:10.1523/JNEUROSCI.5527-08.2009

Copyright $\odot 2009$ Society for Neuroscience $\quad 0270-6474 / 09 / 298704-11 \$ 15.00 / 0$
}

proliferation, fate choice, migration, survival, and differentiation. Recently, some factors classically known for their effects on the vascular system have been found to influence different steps of adult neurogenesis (Carmeliet, 2003; Eichmann et al., 2005; Raab and Plate, 2007; Zacchigna et al., 2008). These include vascular endothelial growth factor-A (VEGF-A), a major activator of angiogenesis in both embryos (Carmeliet et al., 1996; Ferrara et al., 1996) and tumors (Machein and Plate, 2004), which also has been shown to influence NPCs in vitro and in vivo (Jin et al., 2002; Schänzer et al., 2004; Meng et al., 2006). VEGF-A is a member of the VEGF family that includes six different homologous factors: VEGF-A-VEGF-E and placental growth factor (Raab and Plate, 2007). VEGF-A is expressed by glial cells within the SVZ and the RMS (Balenci et al., 2007). VEGF-A functions by binding to the receptor tyrosine kinases VEGF receptor-1 (VEGFR-1) [fmsrelated tyrosine kinase-1 (Flt-1)] (Shibuya et al., 1990; de Vries et al., 1992) and VEGF receptor-2 (VEGFR-2) (fetal liver kinase 1) (Terman et al., 1991). In vitro VEGFR-2 has been shown to transmit VEGF-A-mediated response in neural cells (Cao et al., 2004; Schänzer et al., 2004; Balenci et al., 2007). Furthermore VEGFR-2 signaling directly modulates behavior of retinal progenitor cells (Hashimoto et al., 2006).

Recently, it was reported that another member of the family VEGF-B also exerts neurotrophic effects (Sun et al., 2004, 2006). Whereas VEGF-A is capable to bind to both VEGFR-1 and VEGFR-2, VEGF-B can only activate VEGFR-1 and the corecep- 


\section{LV/SVZ}
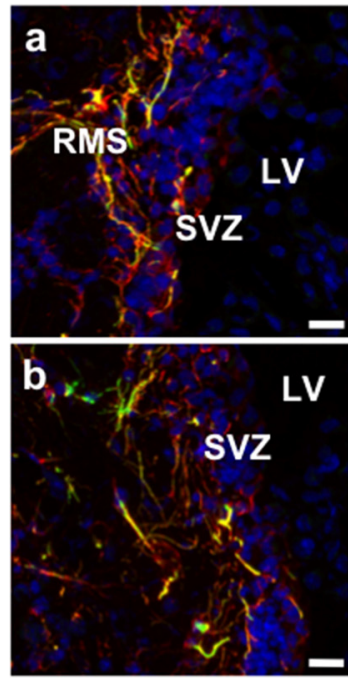

RMS

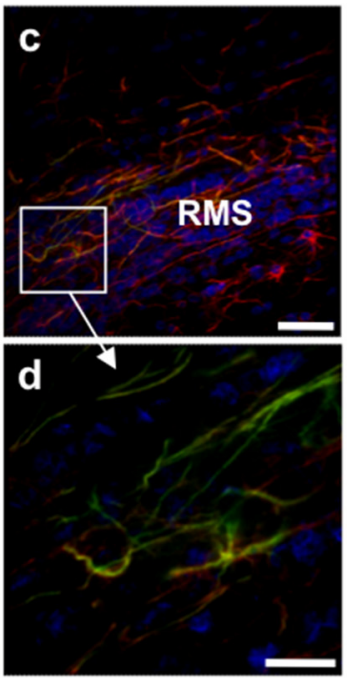

OB

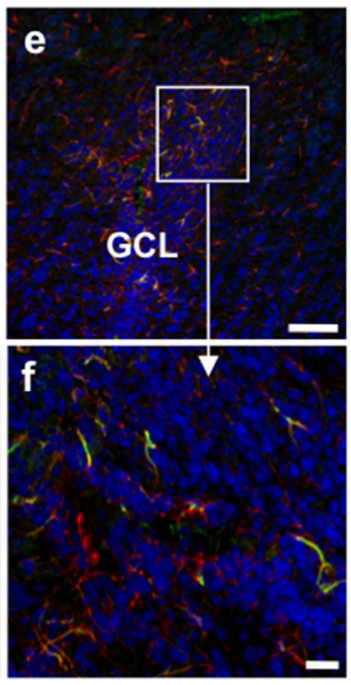

CC

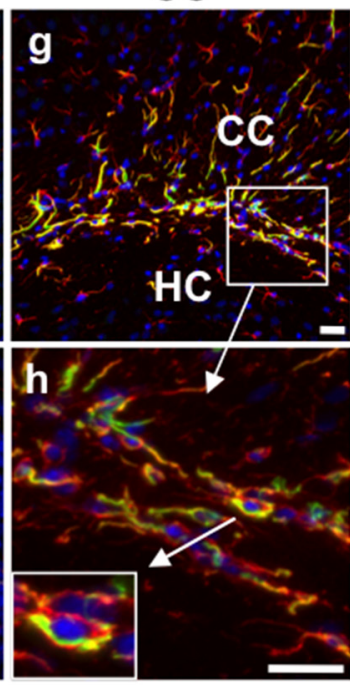

HC

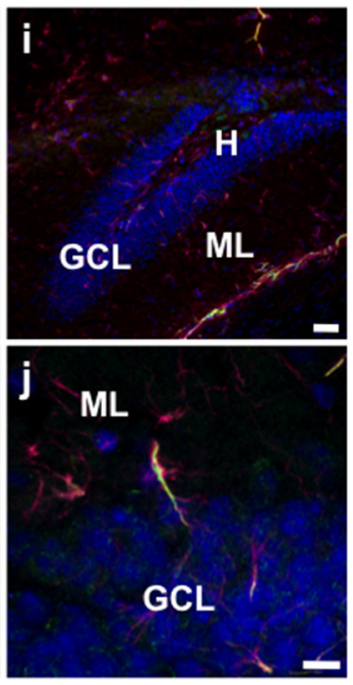

VEGFR-1 GFAP Toto3

Figure 1. Expression of VEGFR-1 in neurogenic areas of the adult mouse brain. $\boldsymbol{a}-\boldsymbol{j}$, Sagittal sections of the brain showing VEGFR-1 expression (green) in GFAP ${ }^{+}$cells (red), counterstained with DAPI (blue) in different brain areas. $\boldsymbol{a}, \boldsymbol{b}$, SVZ of the LV. $\boldsymbol{c}$, Section of adult mouse RMS showing expression of VEGFR-1 (green) throughout the stream in GFAP ${ }^{+}$cells. $\boldsymbol{d}$, Higher magnification of $\boldsymbol{c}$. $\boldsymbol{e}, \boldsymbol{f}$, In the adult mouse $0 B$, expression of VEGFR- 1 (green) was detected in GFAP ${ }^{+}$cells mainly in GCL. $\boldsymbol{f}$, Higher magnification of $\boldsymbol{e}$. $\boldsymbol{g}, \boldsymbol{h}$, Many GFAP ${ }^{+}$cells (red) cells in CC coexpress VEGFR- 1 (green), $\boldsymbol{h}$, Higher magnification of $\boldsymbol{g}$. Inset in $\boldsymbol{g}$ shows an example of clear expression of VEGFR-1 (green) and GFAP (red) in the same cell, nucleus (DAPI, blue). $\boldsymbol{i}$, , sections of adult mouse HC with scattered $\mathrm{GFAP}^{+}$cells (red) expressing VEGFR-1 (green). Scale bars: $\boldsymbol{a}, \boldsymbol{b}, \boldsymbol{f}, \boldsymbol{g}, \boldsymbol{h}, \boldsymbol{j}, 20 \mu \mathrm{m} ; \boldsymbol{c}, \boldsymbol{d}, \boldsymbol{e}, \boldsymbol{i}, 50 \mu \mathrm{m}$. H, Hilus; ML, Molecular layer.

tor Neuropilin-1 (Olofsson et al., 1998; Makinen et al., 1999). However, the role of VEGFR-1 for neurogenesis in the adult brain has not been elucidated so far.

Here, we characterized the expression of VEGFR-1 in regions involved in adult neurogenesis by immunofluorescence. Using a domain-specific knock-out mouse lacking the VEGFR-1 intracellular domain $\left(\right.$ Flt-1TK $\left.{ }^{-\prime-}\right)$ (Hiratsuka et al., 1998), we identified VEGFR-1 as a negative regulator of adult olfactory neurogenesis and RMS migration, acting predominantly via a paracrine mechanism. Our data show that RMS migration is dependent on and can be modified by VEGF-A levels that affect VEGFR-2 activation in NPCs within the adult anterior SVZ (aSVZ) and RMS.

\section{Materials and Methods}

Animals. All animal experiments were approved by the local government and were conducted according to the local guidelines and law. Flt$1 T K^{-1-}$ mice, generated previously (Hiratsuka et al., 1998), were maintained in a C57BL/6 background, and C57BL/6 mice (Charles River) were used as wild-type (WT) controls. For functional in vivo analysis, we used 6- to 16-week-old males.

Surgery. Before VEGF-A infusions, mice were injected intraperitoneally with bromodeoxyuridine (BrdU) (Sigma-Aldrich) daily for $5 \mathrm{~d}$. These animals received intracerebroventricular infusions via osmotic minipumps according to a protocol established previously in rats (Kuhn et al., 1997; Schänzer et al., 2004). Flt-1TK ${ }^{-1-}$ and control animals received either recombinant mouse VEGFA $_{165}(2.4 \mathrm{ng} / \mathrm{d}$; Reliatech) or artificial CSF (aCSF) at a flow rate of $0.5 \mu \mathrm{l} / \mathrm{h}$ for $6 \mathrm{~d}$. Animals with incorrect cannula placement were excluded from the analysis. Some animals received $5 \mathrm{ng}$ of recombinant mouse $\mathrm{VEGFA}_{165}$ in a single injection into the left LV and were killed after $4 \mathrm{~h}$.

Labeling of newly formed cells. To label newly formed cells, different protocols of BrdU intraperitoneal injections were performed $(50 \mathrm{mg} / \mathrm{kg}$ body weight): (1) a single injection, $3 \mathrm{~h}$ before the animals were killed, that preferentially labeled rapidly dividing cells in this short time interval; and (2) daily injections for $5 \mathrm{~d}$ to label and follow large cell numbers.

Antibodies. Anti-PECAM-1/CD-31 (PharMingen), anti-BrdU (Harlan-Seralab), anti-glial fibrillary acidic protein (GFAP), antiDoublecortin (DCX), and neuronal-specific nuclear protein (NeuN)
(Millipore Bioscience Research Reagents), anti-GFAP (Dako), antiVEGFR-1, anti-VEGFR-2 (Santa Cruz Biotechnology), anti-VEGF-A (Zymed and R \& D Systems) anti-pVEGFR-2-Y996 and pVEGFR-2Y951, anti-pFAK, anti-pPaxillin, anti-p38 mitogen-activated protein kinase (MAPK), and anti-H2A (Cell Signaling Technology), antipVEGFR-2-Y996 (Abgent), anti- $\beta$ III-Tubulin/TujI (Promega), mouse anti-Nestin (BD Biosciences Discovery Labware), mouse antiNeurofilament and anti-Tubulin (Sigma), mouse anti-proliferating cell nuclear antigen (PCNA) (Dianova), and mouse anti-tyrosine hydroxylase (Calbiochem).

BrdU detection and stereological analysis. Perfusions, sectioning, BrdU immunohistochemistry, and stereological analysis were performed as described previously (Schänzer et al., 2004). Serial sections (240-160 $\mu \mathrm{m}$ interval) were analyzed using a semiautomatic stereology system (MicroBrightField). Counting frames and sampling grid sizes were as follows (in $\mu \mathrm{m})$ : for the RMS, $50 \times 50$ and $80 \times 80$; for the $\mathrm{OB}$ granular cell layer (GCL), $60 \times 60$ and $250 \times 250$, and for the corpus callosum (CC), $100 \times$ 100 and $150 \times 150$, respectively. For the LV and the HC, no counting frames were used. Cells that intersected the uppermost focal plane or the lateral exclusion boundaries of the counting frames were not counted.

Serial sections in a $240 \mu \mathrm{m}$ interval were stained for triple immunofluorescence as described previously (Schänzer et al., 2004). For each brain and region, $50 \mathrm{BrdU}$-positive $\left(\mathrm{BrdU}^{+}\right)$cells were randomly selected and analyzed for double staining using confocal microscopy. The number of newly generated cells coexpressing a certain marker was calculated by multiplication of the resulting percentage for each group and marker with the total number of $\mathrm{BrdU}^{+}$cells.

Immunofluorescence. For VEGFR-1 immunohistochemistry, removed brains were immediately snap frozen for cryosectioning. For all other immunolabelings, animals were perfused with $4 \%$ paraformaldehyde (PFA)/PBS as described previously (Schänzer et al., 2004). In all immunohistochemical experiments, omission of the primary antibody served as control. IgG controls excluded nonspecific binding of primary antibodies. Cell-type-specific expression of VEGFR-1 was assayed by multiimmunofluorescence labeling on acetone-fixed cryosections using the M.O.M. immunodetection kit (Vector Laboratories). For detection, secondary antibodies conjugated to Alexa Fluor568/488/cyanine 5 (Invitrogen) were used. Sections were counterstained with nuclear markers Toto-3 iodide or 4', 6' -diamidino-2-phenylindole (DAPI) (Invitrogen). 
Evaluation of double staining was performed using a multi-fluorescence microscope (Leica) or a confocal scanning laser microscope (Nikon C1si).

Combined in situ hybridization/immunohistochemistry. In situ hybridization and riboprobe generation were performed as described previously (Beck et al., 2002). To detect VEGFR-1 mRNA, the cDNA template mflt20 dXBa (Breier et al., 1995) was used (gift from Dr. Georg Breier, Dresden, Germany). After color reaction, the slides were rinsed in PBS and overlaid for $30 \mathrm{~min}$ with double-staining enhancer (Zymed). GFAP immunohistochemistry was performed as described above. For detection of biotinylated secondary antibodies, the Vectastain ABC Elite kit and AEC Substrate kit (both from Vector Laboratories) were used according to the protocols of the manufacturer.

Terminal deoxynucleotidyl transferasemediated biotinylated UTP nick end labeling. Terminal deoxynucleotidyl transferasemediated biotinylated UTP nick end labeling (TUNEL) assay was performed on acetonefixed cryosections using the Apoptag Apoptosis Detection kit (Millipore Bioscience Research Reagents). Sections were postfixed in 1\% PFA/ PBS and ethanol/glacial acetic acid. The sections were washed in PBS and incubated with equilibration buffer for 10-30 s, followed by TdT-reaction solution for $1 \mathrm{~h}$ at $37^{\circ} \mathrm{C}$ and a stop buffer for $10 \mathrm{~min}$. The TdT-reaction solution was diluted 1:2 with TUNEL Dilution Buffer (Roche). After blocking for $1 \mathrm{~h}$, sections were incubated with anti-digoxigenin-alkaline phosphatase antibody (Roche) for $1 \mathrm{~h}$. TUNEL $^{+}$cells were visualized with nitrobluetetrazolium-

chloride/5-bromo-4-chlor-indolyl-phosphate solution. For TUNEL analysis, no counting frames were used, and six sections in an interval of $120 \mu \mathrm{m}$ were counted.

Protein extraction, ELISA, and Western blot. Proteins were extracted in lysis buffer containing $100 \mathrm{~mm} \mathrm{NaCl}, 20 \mathrm{~mm}$ Tris-HCl, pH 7.5, 1 mM EDTA, protease inhibitor (Roche), and phosphatase inhibitor solutions (Sigma). ELISA was performed using the Quantikine mouse sFlt-1 ELISA kit (R \& D Systems) according to the protocol of the manufacturers. For Western blot, samples diluted in loading buffer (62.5 mм Tris$\mathrm{HCl}, \mathrm{pH} 6.8,2 \%$ SDS, $10 \%$ glycerol, $710 \mathrm{~mm} \beta$-mercaptoethanol, and $0.01 \%$ bromophenol blue) were separated on $4-15 \%$ Tris- $\mathrm{HCl}$ gels (Bio-Rad) and blotted to Immobilon polyvinylidene difluoride membrane (Millipore). HRP-conjugated secondary antibodies (Calbiochem) were detected with SuperSignal (Pierce).

Vascularization. Serial sagittal sections stained with the endothelial cell marker anti-PECAM-1/CD-31 were analyzed for vessel numbers and size. For each brain region, six view fields $(20 \times)$ were quantified.

SVZ explant cultures. The aSVZ of adult Flt $1 \mathrm{TK}^{-1-}$ and WT mice was dissected from a sagittal slice $(\sim 1 \mathrm{~mm}$ thickness) under sterile conditions. The tissue was cut into $1 \mathrm{~mm}^{3}$ blocks (approximately six explants per brain) and embedded in $60 \mu$ l of Matrigel (BD Biosciences Discovery Labware) on glass slides precoated with poly-L-ornithin (Sigma). After 10 min, Neurobasal-A medium containing 2\% B27 serum supplement, 100 $\mu \mathrm{g} / \mathrm{ml}$ streptomycin, and $100 \mathrm{U} / \mathrm{ml}$ penicillin was added to each well. Additional $40 \mathrm{ng} / \mathrm{ml}$ VEGF-A and $20 \mathrm{ng} / \mathrm{ml} \mathrm{FGF-2} \mathrm{(both} \mathrm{from} \mathrm{R} \mathrm{\&} \mathrm{D)}$ were added. Every $2 \mathrm{~d}$, half of the medium was changed, and new growth factors were added.

Cell migration out of the SVZ explants into the Matrigel was measured with phase-contrast light microscopy and determined by the average b

6000

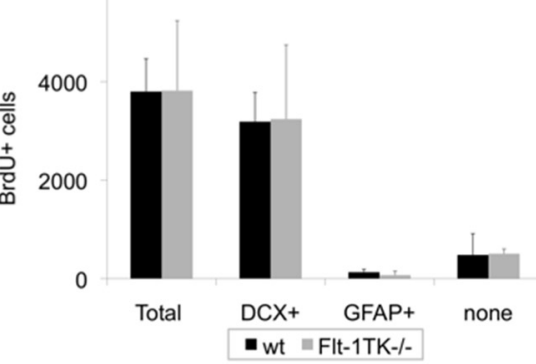

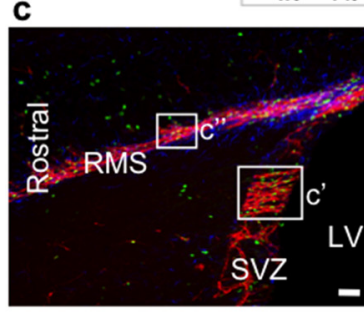
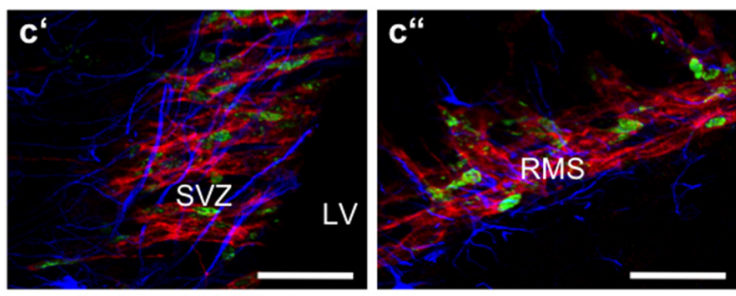

BrdU DCX GFAP

e 1800

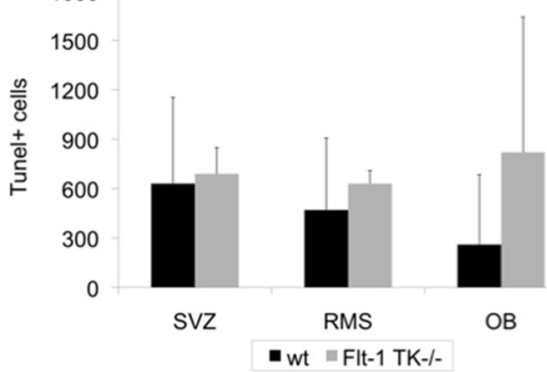

Figure 2. Increased proliferation of subventricular NPCs in Flt-1TK ${ }^{-1-}$ mice. $a$, BrdU immunohistochemistry $3 \mathrm{~h}$ after a single bolus of BrdU showed higher number of BrdU ${ }^{+}$cells in the SVZ of Flt-1TK ${ }^{-/}$mice compared with WT. Triple immunofluorescence as shown in c revealed that the increase in BrdU ${ }^{+}$cells in the SVZ of Flt-1TK ${ }^{-1}$ compared with WT-mice lies within the in which BrdU cells proliferated was similar between both genotypes. $\boldsymbol{e}$, No significant difference in the number of TUNEL-labeled cells was found between Flt- $1 T K^{-\prime-}$ and WT mice. $n=3$.

distance between the explant perimeter and the perimeter formed by the leading edge of migrating cells. Measurements were medians of three different locations. The median migration speed was calculated from the median migration distance of cells from the explants in each group at every time point.

Statistics. All data are the mean \pm SD. Statistical analysis was performed using the unpaired, two-sided Student's $t$ test (Microsoft Excel). Asterisks identify groups that were significantly different ( $p$ value $<0.05$ ) from control groups.

\section{Results}

VEGFR-1 expression in GFAP ${ }^{+}$cells within areas of adult neurogenesis

In the adult mouse brain, strong VEGFR-1 expression was observed in the SVZ of the LV, the RMS, the OB, the HC, and the CC (Fig. 1). Nearly all VEGFR-1 ${ }^{+}$cells expressed GFAP. Threedimensional images revealed clear coexpression of GFAP and VEGFR-1. The anti-VEGFR-1 antibody primarily stained the cell soma and the larger processes of $\mathrm{GFAP}^{+}$cells (supplemental data, available at www.jneurosci.org as supplemental material). In accordance, VEGFR-1 mRNA was detected by in situ hybridization in GFAP-expressing cells labeled by immunohistochemistry (supple- 
a
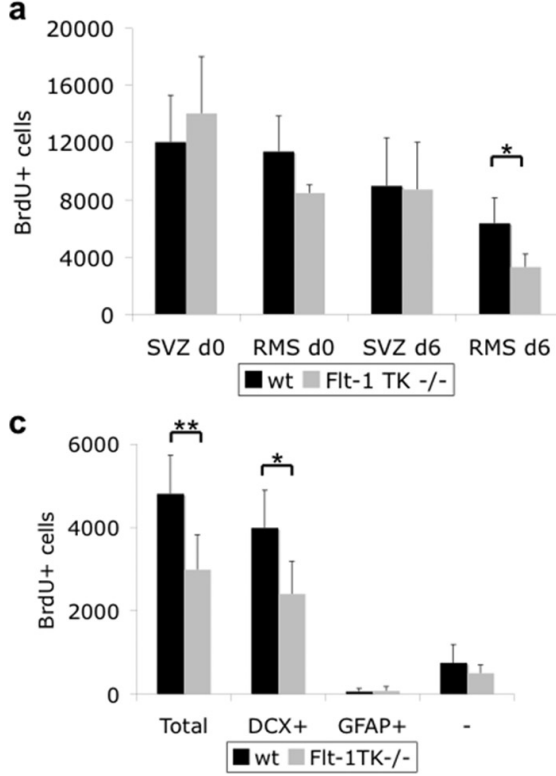

b

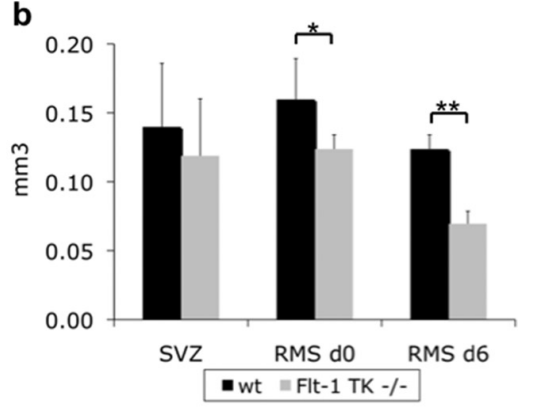

d

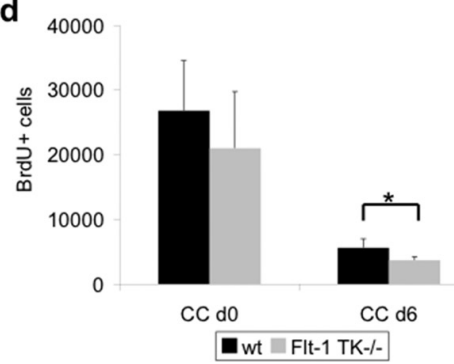

Figure 3. VEGFR-1-signaling deficient FIt-1TK ${ }^{-1-}$ mice display a strong change in migration behavior of NPCs in the RMS. Flt-1TK ${ }^{-1-}$ and WT mice were injected with BrdU on 5 consecutive days, and BrdU-labeled cells were analyzed on the last day of BrdU application (d0) and after 6 additional days (d6). $\boldsymbol{a}$, The RMS of Flt-1TK ${ }^{-1-}$ mice showed less BrdU ${ }^{+}$cells already at day 0 when compared with WT mice. On day 6, BrdU-marked cells were significantly reduced by $47.97 \%$ of the mean. In the SVZ, no quantitative difference in $\mathrm{BrdU}^{+}$cells between genotypes was detected at either time point. ${ }^{*} p<0.0003$. Flt- $1 \mathrm{TK}^{-/-}, n=11$; WT, $n=10 . \boldsymbol{b}$, In Flt-1TK ${ }^{-1-}$ mice, the spreading area of labeled cells within the RMS was significantly smaller than in WT mice. There was no difference between both genotypes in SVZ volume. ${ }^{*} p<0.0006$; ${ }^{* *} p<0.03$. c, Confocal analysis of triple immunofluorescence showed that especially the $\mathrm{DCX}^{+} / \mathrm{BrdU}^{+}$neuronal progenitor cell population is reduced in the RMS of Flt-1TK ${ }^{-1-}$ mice compared with control. ${ }^{*} p<0.02{ }^{* *} p<0.03$. Flt-1TK ${ }^{-1-}, n=11 ;$ WT, $n=10$. $\boldsymbol{d}$, The number and density of BrdU ${ }^{+}$cells entering the CC was significantly reduced in Flt-1TK ${ }^{-/-}$mice on day 6 (compared with WT mice). ${ }^{*} p=0.034$. Day 0: Flt-1TK ${ }^{-1-}, n=5 ; \mathrm{WT}, n=7$. Day 6: Flt-1TK ${ }^{-1-}, n=4 ; \mathrm{WT}, n=5$.
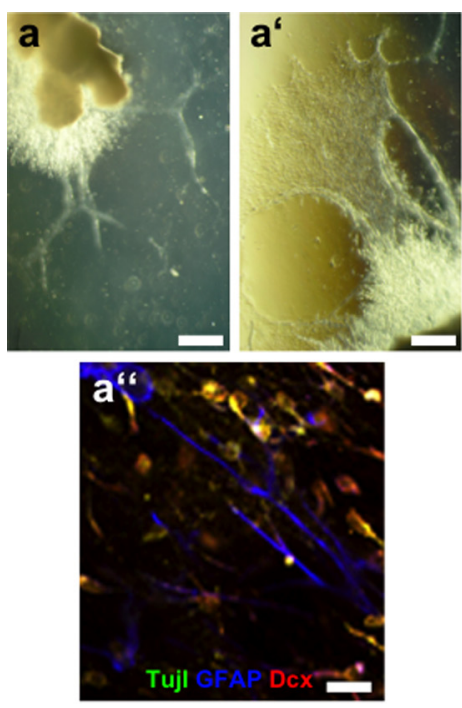

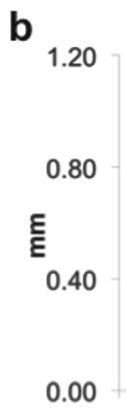

C

Migration rate of cells from SVZ-explants
\begin{tabular}{|l|c|c|c|}
\hline in $\mu \mathrm{m} / \mathrm{h}$ & Day 0-7 & Day 7-9 & Day 9-13 \\
\hline TK-/- & 1.17 & 1.53 & 3.85 \\
\hline WT & 0.47 & 0.48 & 1.62 \\
\hline
\end{tabular}

Figure 4. SVZ explants from VEGFR-1-signaling-deficient $F l t-1 T K^{-1-}$ mice show increased migration speed in vitro. SVZ tissue from Flt-1TK $K^{-1-}$ and WT mice was cultured in Matrigel for 13 d. $\boldsymbol{a}$, Out-migrating cells form networks of highly compacted cells that express neural markers. Scale bars: $\boldsymbol{a}, 500 \mu \mathrm{m} ; \boldsymbol{a}^{\prime}, 100 \mu \mathrm{m} ; \boldsymbol{a}^{\prime \prime}, 10 \mu \mathrm{m}$. $\boldsymbol{b}$, Cells of SVZ explants derived from Flt-1TK ${ }^{-1-}$ have migrated farther than those derived from WT mice at every time point. ${ }^{*} p=0.008 ;{ }^{* *} p=0.003 ;{ }^{* * *} p<0.02$.c Cells from Flt-1TK ${ }^{-1-}$ SVZ explants migrated more than two times faster than cells from WT SVZ explants. FIt-1TK ${ }^{-1-}, n=22 ; \mathrm{WT}, n=15$.

mental Fig. S1c, available at www.jneurosci.org as supplemental material).

In detail, abundant $\mathrm{GFAP}^{+} / \mathrm{VEGFR}-1^{+}$cells were detected close to the LV in the lateral, dorsal, and medial SVZ, predominantly in the aSVZ but also posterior (Fig. $1 a, b$ ). In the (sub)ependymal layer, a perinuclear dotted staining pattern was observed frequently (supplemental Fig.S1a, available at www.jneurosci.org as supplemental material). $\mathrm{GFAP}^{+} /$VEGFR- ${ }^{+}$cells were observed along the entire RMS (Fig. $1 c, d)$ and within the CC (Fig. 1g,h). GFAP ${ }^{+} /$ VEGFR- ${ }^{+}$cells in the OB (Fig. 1e,f) were located mainly in the GCL but also in the plexiform layer (PL) and periglomerular layer (PGL). In the HC, the VEGFR-1 ${ }^{+}$cells were less abundant (Fig. 1e).

In addition, $\mathrm{GFAP}^{+}$cells in the subependyma of the third ventricle displayed a strong VEGFR-1 expression (data not shown). In other brain regions, VEGFR-1 was barely detectable. Costaining of VEGFR-1 with the mature neuronal marker NeuN (data not shown) and Nestin (supplemental Fig.S1e, available at www.jneurosci.org as supplemental material), a marker for NPCs (Lendahl et al., 1990), did not show any cell type expressing VEGFR-1 other than GFAP ${ }^{+}$cells. VEGFR-1 was not detected in endothelial cells, marked with CD31. However, VEGFR $-1^{+} / \mathrm{GFAP}^{+}$cells are close to and often enwrap CD $31^{+}$vascular structures. (supplemental Fig.S1f, available at www. jneurosci.org as supplemental material). Although VEGFR-1 is expressed in neurogenic regions of the adult brain, we observed no expression in proliferating cells, marked by PCNA (supplemental Fig.S1e, available at www.jneurosci.org as supplemental material).

VEGFR-1 signaling modulates adult olfactory neurogenesis at multiple levels $\mathrm{GFAP}^{+}$cells actively influence adult neurogenesis (Ma et al., 2005). Therefore, the revealed expression pattern of VEGFR-1 in the adult mouse brain prompted us to ask whether VEGFR-1 is involved in the regulation of adult neurogenesis. To address this question, we used a domain-specific knock-out mouse in which the VEGFR-1 signaling domain is genetically deleted (Flt-1TK $\left.{ }^{-/-}\right)$, whereas the ligand-binding domain is still intact and functional (Hiratsuka et al., 1998). Newly formed cells were labeled by intraperitoneal injection with BrdU.

\section{VEGFR-1 signaling negatively regulates proliferation of adult NPCs}

To examine a potential function of VEGFR-1 for NPC proliferation, we compared local proliferation activity of Flt$1 \mathrm{TK}^{-/-}$and WT mice in the aSVZ, one of the main sites of proliferation activity within the adult brain, and in the RMS. To determine the proliferation activity, BrdU incorporation was analyzed $3 \mathrm{~h}$ after a BrdU pulse (Cameron and McKay, 2001). Quantification of BrdU-labeled cells and analysis of triple immu- 
nofluorescence of BrdU, NPC marker Doublecortin (DCX), and glial marker GFAP (Fig. 2c) showed that, in the aSVZ, proliferation of $\mathrm{DCX}^{+}$NPCs was significantly increased in Flt-1TK ${ }^{-1-}$ compared with WT mice, whereas BrdU ${ }^{+}$cells expressing neither DCX nor GFAP were reduced (Fig. 2a). Although the boost of proliferation activity was detected throughout the aSVZ, the increase was more pronounced in the lateral than in the medial region. In contrast, proliferation activity of migrating NPCs in the RMS was not affected (Fig. 2b). The volume of the HC (data not shown), the aSVZ, and the area in which cells proliferated within the RMS was similar between both groups (Fig. 2d). Together, this suggests that VEGFR-1 signaling deletion specifically enhances the proliferation of subventricular NPCs.

\section{VEGFR-1 is a regulator of olfactory NPC} migration in the adult brain

Expression of VEGFR-1 in GFAP $^{+}$cells along the entire RMS led us to hypothesize that VEGFR-1 is expressed in the glial tube surrounding the migrating NPCs and exerting a regulatory role in NPC migration. To track the newly formed cells in vivo, Flt-1TK ${ }^{-/-}$and WT mice received daily BrdU injections for 5 consecutive days, and their brains were analyzed on the last day of BrdU application (day 0) and after $6 \mathrm{~d}$ (day 6). Analysis on day 0 after injections of BrdU over a longer time period identifies a combination of actively proliferating cells and migrating cells that already left the cell cycle during the injection period. Analysis on day 6 mainly gives cues about migrating cells.

Within the aSVZ, no difference of $\mathrm{BrdU}^{+}$cell quantity between both genotypes was detectable on days 0 and 6 . However, already on day 0 , we observed fewer $\mathrm{BrdU}^{+}$cells within the RMS of Flt-1TK ${ }^{-/-}$than in WT mice. By day 6 , BrdU-marked cells were significantly reduced $(47.97 \%$ of the mean) (Fig. $3 a$ ) in Flt-1TK ${ }^{-1-}$ mice. Confocal analysis of triple immunofluorescence (BrdU, GFAP, and DCX) showed that specifically the $\mathrm{DCX}^{+} / \mathrm{BrdU}^{+}$cell population was diminished (Fig. 3c). In addition, the spreading area of migrated $\mathrm{BrdU}^{+}$cells was significantly smaller in Flt-1TK${ }^{-/-}$than in WT mice (Fig. $3 b$ ). Altogether, this indicates a strong aberration in RMS migration of NPCs in vivo in the VEGFR-1-signalingdeficient Flt-1TK ${ }^{-1-}$ mice.

Next we investigated the cause of the reduction of $\mathrm{BrdU}^{+}$cells in the RMS of Flt-1TK ${ }^{-1-}$ compared with WT mice. No accumulation of BrdU-labeled cells could be detected in Flt-1TK ${ }^{-/-}$mice in the aSVZ and the rostral extension of the SVZ, in which NPCs coalesce to migrate into the RMS (Fig. $3 a$ ). No difference in apoptosis between both genotypes was found by TUNEL staining (Fig. 2e). One possible explanation for the reduction of NPCs in the RMS could be that more NPCs leave the RMS in Flt-1TK ${ }^{-/-}$ a

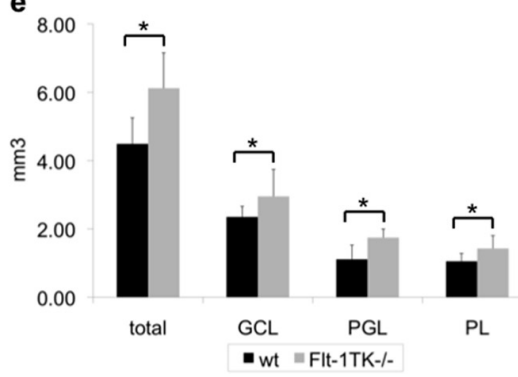

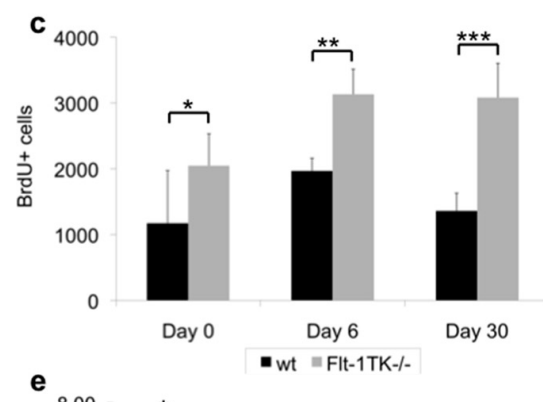

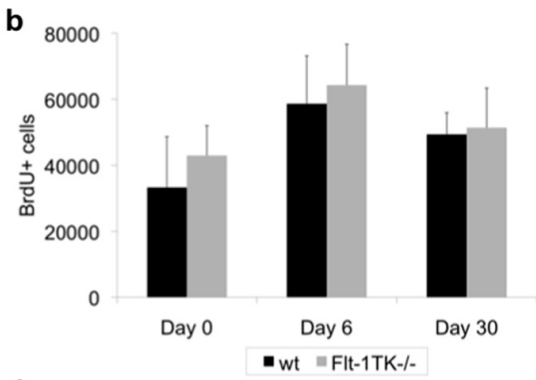

d 10000

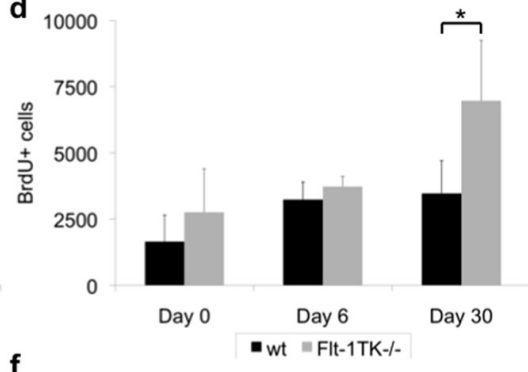

$\mathbf{f}$

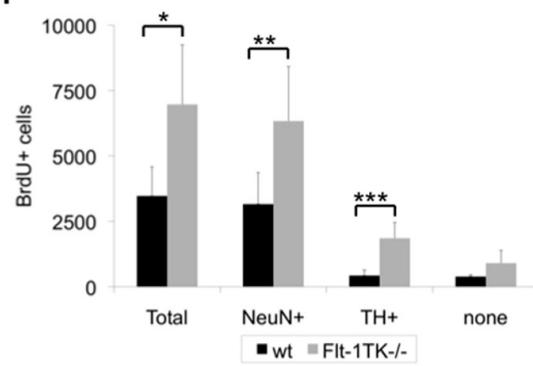

Figure 5. VEGFR-1 deficiency leads to an increased generation of new neurons in the OB resulting in increased OB size. $\boldsymbol{a}$, Schematic drawing of the migration of NPCs into the olfactory bulb. Cells entering the OB detach from the chains and mainly migrate into the inner GCL. A small percentage migrates through the PL (dark gray) into the periglomerular layer (light gray). $\boldsymbol{b}$ - $\boldsymbol{f}$ and WT mice were injected with BrdU on 5 consecutive days, and BrdU-labeled cells were analyzed on the last day of cells than the $\mathrm{GCL}$ of control animals, but this difference did not reach statistical significance. $n=5 . c, \ln$ Flt-1TK ${ }^{-/-}$ mice, a significantly higher number of BrdU-labeled cells migrate through the $\mathrm{PL} .{ }^{*} p<0.05 ;{ }^{* *} p=0.006 ;{ }^{* * *} p<0.0002 . d$, The wave of BrdU reached the PGL at day 30. Then the number of BrdU ${ }^{+}$cells has more than doubled in the PGL of Flt-1TK ${ }^{-1-}$ than WT mice. ${ }^{*} p=0.017 ; n=5$. $e$, Volumetric analysis of the 0 B revealed that Flt-1TK ${ }^{-1}$ mice had an increased volume of the

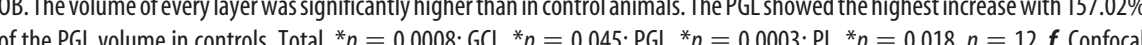
analysis of triple immunofluorescence using the markers anti-BrdU, NeuN, and anti-tyrosine hydroxylase revealed a significant increase in the number of newly formed neurons marked by NeuN in the PGL of Flt-1TK ${ }^{-/-}$compared with WT mice. In addition, the number of cells expressing tyrosine hydroxylase $(\mathrm{TH})$, a marker of dopaminergic neurons, was significantly higher in the PGL of Flt-1TK ${ }^{-1-}$ than in controls. ${ }^{*} p=0.02 ;{ }^{* *} p=0.047 ;{ }^{* * *} p=0.014$. Flt-1TK ${ }^{-1-}, n=5 ;$ WT, $n=4$.

mice. Negligible numbers of $\mathrm{BrdU}^{+}$cells were observed to migrate out of the RMS into the striatum, but many cells entered the overlying CC. Unexpectedly, in the CC of Flt-1TK ${ }^{-1-}$ mice, the number and density of $\mathrm{BrdU}^{+}$cells were significantly lower on day 6 compared with WT mice (Fig. 3d). The volume of the CC was not affected (data not shown). The decline in $\mathrm{BrdU}^{+}$cells in the RMS of Flt-1TK ${ }^{-1}$ appeared thereby to be attributable to neither enhanced apoptosis, an incapability of cells leaving the SVZ, nor an enhanced migration into the CC.

The migration of NPCs was further compared in vitro in SVZ explants cultured in Matrigel. In this system, cells of SVZ explants originating from $\mathrm{Flt}-1 \mathrm{TK}^{-/-}$mice migrated a significantly greater distance into the Matrigel than cells from WT mice (Fig. $4 b)$. The out-migrating cells were NPCs or glial cells indicated by DCX/ $\beta$ III-Tubulin or GFAP expression, respectively (Fig. $4 a$ ). Cells from Flt-1TK ${ }^{-1-}$ explants exhibited a more than doubled migration speed of control explants, which implicates an enhanced migration in Flt-1TK ${ }^{-/-}$mice (Fig. 4c). 


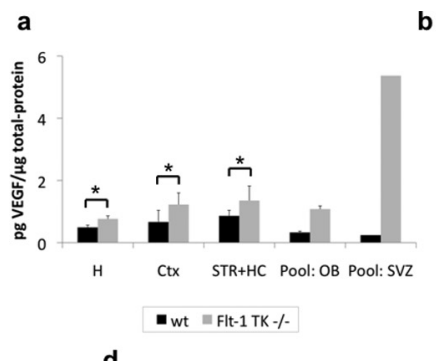

d

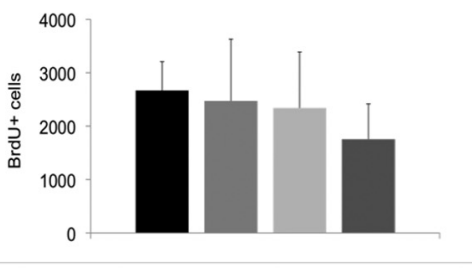

-WT aCSF $\quad$ FIt-1TK aCSF $\quad$ "WT VEGF $\quad "$ Flt-1TK VEGF
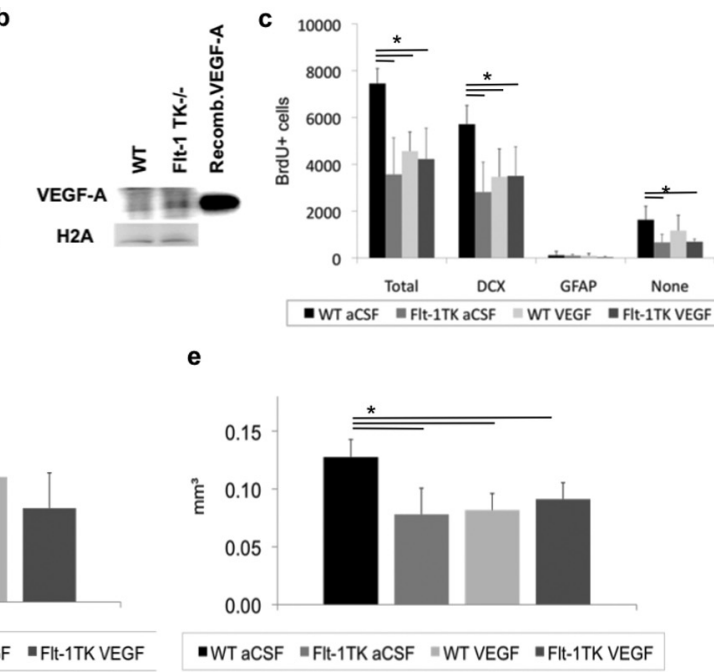

Figure 6. VEGF-A infusion in WT mice is sufficient to mimic the migration phenotype observed in Flt-1TK ${ }^{-/-}$mice. $\boldsymbol{a}$, VEGF-A protein of brain tissue of Flt-1TK ${ }^{-1-}$ and WT mice was quantified by ELISA. Flt-1TK ${ }^{-1-}$ mice display higher levels of VEGF-A protein in different brain areas compared with controls. Pool, Tissue from three brains. Hemisphere, ${ }^{*} p=0.02 ; \operatorname{cortex}^{*} p=$ 0.026 ; striatum $+\mathrm{HC},{ }^{*} p=0.0075 . n=5$. $\boldsymbol{b}$, Western blot for VEGF-A confirms increased amount of VEGF-A protein in Flt-1TK ${ }^{-1-}$ mice. Histone 2 A serves as loading control. $c-e$, Flt-1TK ${ }^{-/-}$and control animals received BrdU injections (intraperitoneally) on 5 consecutive days. After the last injection, osmotic minipumps were implanted intracerebroventricularly to deliver VEGF-A or aCSF as control for $6 \mathrm{~d}$. c, Infusion of VEGF-A into the LV of WT mice decreased the number of BrdU-labeled cells in the RMS on day 6 to the level of Flt-1TK ${ }^{-1-}$ mice. The number of BrdU-positive cells in Flt-1TK ${ }^{-1-}$ mice did not change with VEGF-A infusions. The reduction was mainly in the $\mathrm{BrdU}^{+} / \mathrm{DCX}{ }^{+}$cell population in Flt-1TK ${ }^{-/-}$. Total, ${ }^{*} p<0.001 ; \mathrm{DCX},{ }^{*} p<0.01$. The number of BrdU ${ }^{+}$cells in the RMS of Flt-1TK ${ }^{-1-}$ mice did not change with VEGF-A infusions. ${ }^{*} p=0.0009 ;{ }^{* *} p=0.0001$; ${ }^{* * *} p=0.0008$. d, VEGF-A infusions did not change the number of BrdU + cells detected in the SVZ on day 6.e, VEGF-A infusion was sufficient to reduce the spreading area of migrating labeled BrdU cells within the RMS in WT mice to the size off this area measured in Flt-1TK ${ }^{-1-}$ mice. ${ }^{*} p<0.05$. Flt-1TK ${ }^{-/-}$(aCSF), $n=3$; Flt-1TK ${ }^{-1-}$ (VEGF), $n=5$; WT (aCSF), $n=6$; WT (VEGF), $n=7$. Ctx, Cortex; $\mathrm{H}$, hemisphere; STR, striatum.

To examine whether the altered migration pattern of NPCs within the RMS in vivo resulted in cellular changes in the $\mathrm{OB}$, $\mathrm{BrdU}^{+}$cells were analyzed in the different OB layers. At each time point (days 0, 6, and 30), greater numbers of BrdU cells were detected in the GCL of the OB of Flt-1TK ${ }^{-/-}$mice compared with WT mice, although differences were not statistically significant (Fig. 5b). Surprisingly, in Flt-1TK ${ }^{-1-}$ mice, numbers of BrdUlabeled cells were increased in the outer layers of the OB. On days 0,6 , and 30 , significantly more cells marked with BrdU were detected within the PL of Flt-1TK ${ }^{-/-}$mice (peak on day 30 with $126.3 \%$ of control) (Fig. 5 c). At day 30 , additional $\mathrm{BrdU}^{+}$cells located in the PGL were significantly increased $(+100.84 \%)$ compared with WT controls (Fig. $5 d$ ). In summary, Flt-1TK ${ }^{-1-}$ exhibited an enhanced migration of BrdU-labeled cells into the outer layers of the OB when compared with WT mice. This indicates that, in Flt-1TK ${ }^{-1-}$ mice, there is a constant greater supply of newly formed cells to the OB than in WT mice. This should lead to an increase in size of the OB structure. Indeed, Flt-1TK ${ }^{-1-}$ mice possess a significantly enlarged OB $(+36.29 \%)$, with the greatest gain of volume in the PGL $(+57.02 \%)$ (Fig. 5e).

\section{Deletion of VEGFR-1 increases neuronal differentiation and changes interneuron subtype composition within the adult OB}

Triple immunofluorescence on day 30 after the last BrdU injection revealed no difference in neuronal differentiation of $\mathrm{BrdU}^{+}$ cells in the GCL (data not shown), in which 95\% of all surviving cells that reach the $\mathrm{OB}$ terminate their migration and differentiate into neurons (Petreanu and Alvarez-Buylla, 2002; Winner et al., 2002). In contrast, the PGL of Flt-1TK ${ }^{-/-}$mice showed a vast increase in BrdU-labeled cells that adapted a neuronal phenotype determined by coexpression of neuronal marker NeuN. (Fig. 5f). Astonishingly, the number of $\mathrm{BrdU}^{+}$cells expressing tyrosine hydroxylase, an enzyme specifically expressed by dopaminergic neurons, was significantly elevated in Flt-1TK ${ }^{-/-}$mice (Fig. $5 d$ ). Together, these results point to a regulatory role for VEGFR-1 in OB neurogenesis and especially in the differentiation of dopaminergic olfactory interneurons.

\section{VEGFR-1 signaling deficiency does not affect hippocampal neurogenesis} The effects of VEGFR-1 deletion on olfactory neurogenesis lead us to investigate whether VEGFR-1 is also a regulator of neuronal development in the second major site of adult neurogenesis. To address this, we counted newly formed cells in the hippocampi of the different study groups mentioned above. Flt-1TK ${ }^{-1-}$ mice and WT mice showed comparable numbers of BrdU-labeled cells in all hippocampal layers $3 \mathrm{~h}$ after a BrdU pulse [actively proliferating cells (Fig.S2a, available at www. jneurosci.org as supplemental material)] and on day 0 [proliferating and migrating cells (Fig.S2b, available at www.jneurosci. org as supplemental material)] and day 30 [mainly differentiated cells (Fig.S2c, available at www.jneurosci.org as supplemental material)] after successive daily BrdU injections for $5 \mathrm{~d}$. These data imply that VEGFR-1 does not regulate hippocampal neurogenesis.

\section{VEGFR-1 regulates RMS migration via alterations of VEGF-A protein levels}

Flt-1TK ${ }^{-1-}$ mice exhibit higher levels of VEGF-A protein in brain tissue lysates

Our in vivo results together with the expression of VEGFR-1 in $\mathrm{GFAP}^{+}$cells suggest that VEGFR-1 affects adult neurogenesis in a paracrine mechanism. VEGF-A, a ligand for VEGFR-1, is known to affect neural proliferation and neurogenesis in vitro and in vivo and neuronal progenitor migration in vitro (Jin et al., 2002; Zhang et al., 2003; Schänzer et al., 2004). To determine whether VEGF-A accounts for the observed migration phenotype in Flt-1TK ${ }^{-1-}$ mice, protein levels were measured by ELISA and Western blot. Indeed, Flt-1TK ${ }^{-\prime-}$ exhibited significantly elevated VEGF-A levels in the brain (Fig. 6a,b).

VEGF-A infusion is sufficient to induce the Flt- $1 \mathrm{TK}^{-/-}$migration phenotype in WT mice

To tackle the question whether VEGF-A is responsible for the observed phenotype associated with migration, we wanted to see whether VEGF-A infusion alters the numbers and/or cell-type marker expression of newly formed cells in the RMS and SVZ in $v i v o$. For this, Flt-1TK ${ }^{-1}$ and WT mice received daily BrdU injections for 5 consecutive days. Thereafter, VEGF-A was infused intracerebroventricularly via osmotic minipumps for $6 \mathrm{~d}$ during the migration period of NPCs, i.e., after BrdU labeling. The mice were killed on day 6 as before. Stereological analysis of BrdU- 
positive cells showed no difference in the aSVZ as expected (data not shown). However, intracerebral infusion of VEGF-A in WT mice resulted in the phenotype observed previously in Flt-1TK ${ }^{-1-}$ mice (Fig. 2). Compared with WT mice that received aCSF, the number and the spreading area of the migrating BrdU-labeled cells within the RMS were reduced in WT mice that had received VEGF-A to a similar level than in Flt-1TK ${ }^{-/-}$mice (Fig. 6c,e). Infusion of VEGF-A into the brain of Flt$1 T K^{-1-}$ mice did not lead to additional changes (Fig. $6 c, e$ ). Phenotypic analysis of $\mathrm{BrdU}^{+}$cells by triple immunofluorescence confirmed that specifically $\mathrm{DCX}^{+} /$ $\mathrm{BrdU}^{+}$cells were reduced, which resembles the phenotype found in Flt-1TK ${ }^{-/-}$ (Fig. 6c).

In summary, these data clearly show that elevated VEGF-A protein levels in the brains of Flt-1TK ${ }^{-/-}$mice are sufficient to alter the migration path and speed of NPCs and that the increase in VEGF-A protein in this mice is responsible for the paracrine effect on NPC migration in these mice.

VEGFR-1 deletion and increased VEGF-A protein levels increase VEGFR-2

phosphorylation in NPCs of the aSVZ and the RMS

To further explore how VEGFR-1 deletion and VEGF-A regulate adult olfactory neurogenesis, we compared the activation of VEGFR-2 in the brains of WT and Flt$1 T K^{-1-}$ mice that had received either aCSF or VEGF-A intracerebrally for $6 \mathrm{~d}$ (see above). Control mice (WT, aCSF) exhibited only weak phosphorylation of VEGFR- 2 in DCX ${ }^{+}$cells in the aSVZ and the RMS. In contrast, Flt-1TK ${ }^{-1-}$ mice (Flt$1 \mathrm{TK}^{-/-}$, aCSF) showed a strong increase in VEGFR-2 phosphorylation in $\mathrm{DCX}^{+}$cells within the SVZ and the entire RMS (Figs. 7, 8) (supplemental Fig. S3b, available at www.jneurosci.org as supplemental material). The same staining pattern and intensity was seen in WT and Flt-1TK ${ }^{-/-}$mice that had received VEGF-A in the SVZ (Fig. 7) and the RMS (Fig. 8). These results were confirmed with a second antibody directed against phosphoVEGFR-2 (data not shown). Western blots further confirmed elevated levels of VEGFR-2 tyrosine phosphorylation in lysates of rostral forebrain tissue of Flt-1TK ${ }^{-1-}$ mice compared with WT mice (Fig. $8 b$ ). Phospho-VEGF-2 was also increased in mice that received intracerebral VEGF-A (Fig. 8c).

Most of the phospho-VEGFR-2 ${ }^{+}$cells coexpressed the NPC markers polysialic acid-neural cell adhesion molecule and TujI (supplemental Fig.S3c, available at www.jneurosci.org as supplemental material). Interestingly, phosphorylation of VEGFR-2 within the SVZ was regionally restricted to the anterior part, the major area of NPCs proliferation. Immunoreactivity of phosphoVEGFR-2 was barely detectable in the dorsal and posterior SVZ (supplemental Fig.S3a, available at www.jneurosci.org as supplemental material). Interestingly, VEGFR-2 phosphorylation was not seen in the OB. Although weaker expression of DCX persists in NPCs within the OB, VEGFR-2 phosphorylation is completely abolished when NPCs detach from the RMS and enter the GCL (Fig. 8a).

In summary, these results show a regional diverse action of VEGF-A within the SVZ and point toward a specific function of VEGFR-2 in migrating progenitor cells of the aSVZ and RMS.

It is noteworthy that, in brain lysates of Flt-1TK ${ }^{-1-}$ mice, the enhanced VEGFR-2 phosphorylation was accompanied by a vast decline in phosphorylation of p38MAPK, which has been shown to oppose VEGF-A signaling in neuroblastoma (Gomes and Rockwell, 2008) and human umbilical vein endothelial cells (Yilmaz et al., 2003). Concurrently, slightly increased phosphorylation of Paxillin, a component of the focal adhesion that is known to play a regulatory role in VEGF-induced endothelial cell migration (Kanno et al., 2000), was detected in brain lysates (Fig. $8 b)$.

\section{Elevated VEGF-A levels in Flt-1 $\mathrm{TK}^{-/-}$mice do not alter} brain vascularization

VEGF-A is a major regulator of developmental angiogenesis and vasculogenesis, pathological angiogenesis, and the homeostasis of the vasculature in adulthood (for review, see Takahashi and Shibuya, 2005; Raab and Plate, 2007). Nonetheless, the increased VEGF-A protein levels in the brains of Flt-1TK ${ }^{-1-}$ mice did not affect the vessel density or size as determined by staining with anti-CD31 (data not shown). Together, our results point toward 

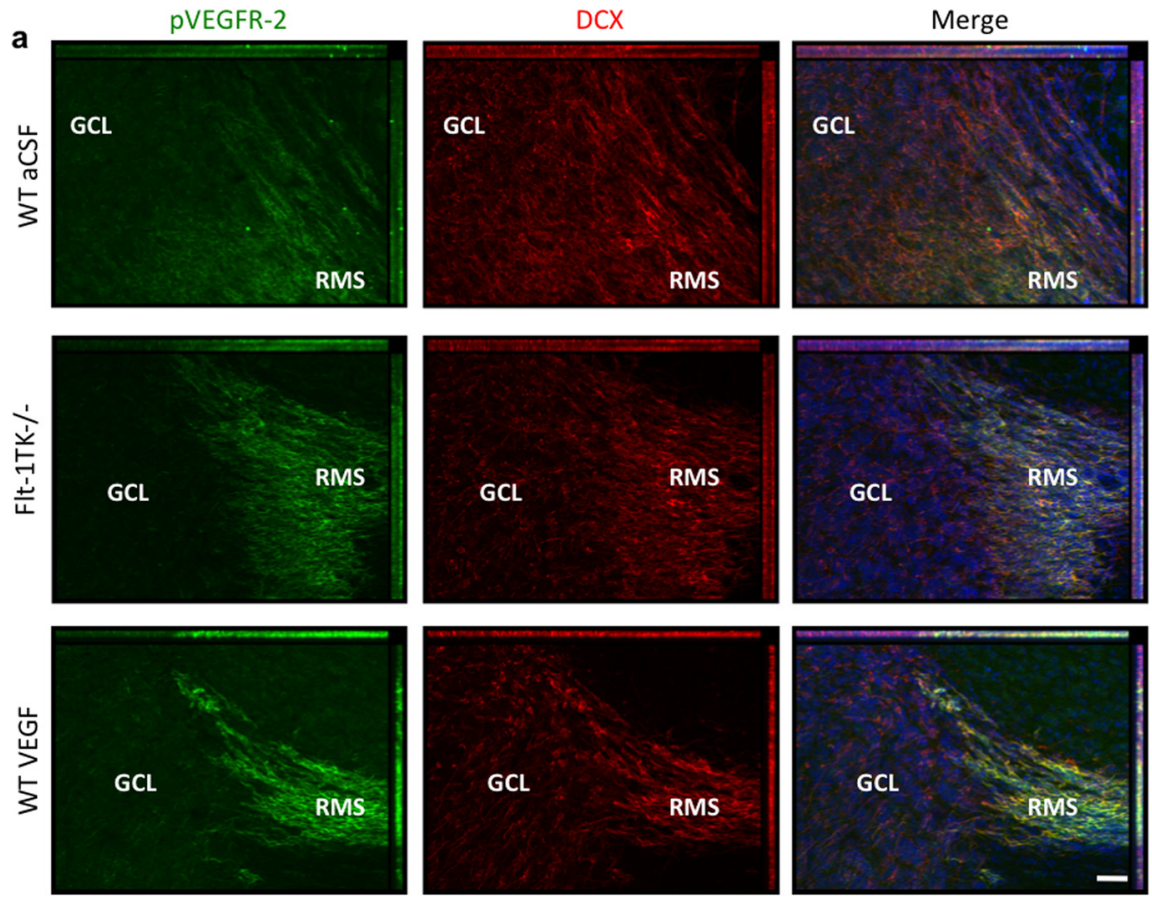

b
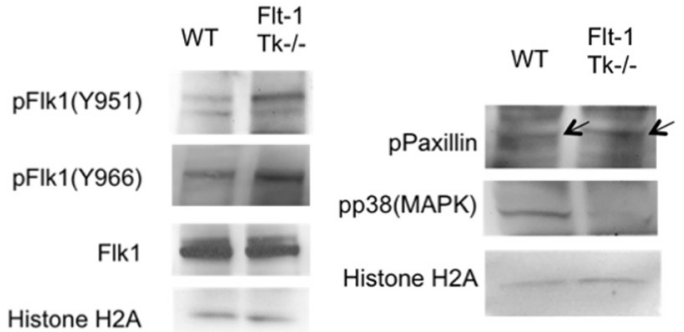

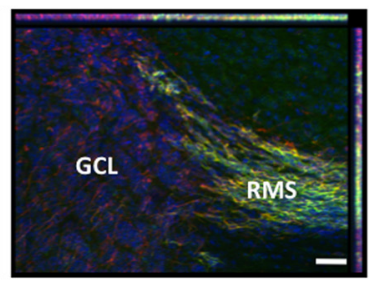

C

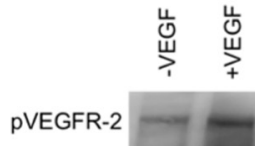

VEGFR-2

strongly in $\mathrm{GFAP}^{+}$cells in the SVZ of the $\mathrm{LV}$, the entire RMS, the OB, the CC, and to a lesser extent in the HC. No significant expression of VEGFR-1 was observed in endothelial cells, but the VEGFR-1 ${ }^{+}$glial cells were often located adjacent to the vasculature. This may reflect a function for VEGFR-1 as part of the glia-vascular niche. Glial cells play key roles in the control of adult neurogenesis, predominantly by expression and secretion of regulatory proteins (for review see, Ma et al., 2005). Current studies demonstrate that proliferating NPCs tend to reside close to blood vessels in the SVZ (Shen et al., 2008; Tavazoie et al., 2008) and that migrating NPCs use vessels as scaffolding and guidance by interacting with extracellular matrix molecules and glial cells (Bovetti et al., 2007). Although vessel size and density were unchanged in Flt-1TK ${ }^{-/-}$mice, the niche could be influenced by the deletion of VEGFR-1 signaling in GFAP ${ }^{+}$cells, and VEGFR-1 thereby regulates neurogenesis via a paracrine mechanism.

Although VEGFR-1 expression was mainly confined to $\mathrm{GFAP}^{+}$cells, the signaling deletion affected NPCs. Compared with WT mice, Flt-1TK ${ }^{-1-}$ mice showed enhanced proliferation of $\mathrm{DCX}^{+}$cells specifically in the aSVZ but not in the RMS or the HC. This implies a region-specific function for VEGFR-1 in the control of proliferation activity of subventricular NPCs.

Seeking the mediator of this effect, we found that Flt-1TK ${ }^{-1-}$ mice exhibited elevated protein concentrations of the ligand VEGF-A in brain tissue. In the adult brain, VEGF-A is expressed by glial cells in the SVZ and RMS (Balenci et al., 2007). We and others have shown previously that exogenous VEGF-A increases proliferation and neurogenesis in adult rats in vivo and that in vitro the neurogenic signal of

a direct effect of VEGF-A on the NPCs via VEGFR-2 rather than an indirect effect caused by increased vascularization.

\section{Discussion}

Here we report a novel role for VEGFR-1 as a negative regulator of adult olfactory neurogenesis. Based on expression profiling and genetic ablation studies in vivo, we show that VEGFR-1 (1) is expressed in $\mathrm{GFAP}^{+}$cells within neurogenic regions of the adult mouse brain, (2) suppresses proliferation in the SVZ, (3) reduces migration of NPCs in the RMS, (4) decreases OB neurogenesis, and (5) influences the cellular composition of the OB. The observed effects are summarized in Figure 9. We further demonstrate that the phenotype associated with NPC migration is mediated mainly via amplified intracerebral levels of the ligand VEGF-A and is accompanied by a regional restricted increase of VEGFR-2 phosphorylation in migrating NPCs. Hence, our study reveals a regulatory role for VEGF-A and its receptors for NPC migration in the RMS in vivo.

In the adult mouse brain, VEGFR-1 was found to be expressed
VEGF-A is transmitted by VEGFR-2 (Jin et al., 2002; Cao et al. 2004; Schänzer et al., 2004; Balenci et al., 2007). Here we present an increase in VEGFR-2 phosphorylation in the SVZ of VEGFR-1 signaling-deficient mice, as well as in mice that had intracerebrally received VEGF-A. Together, these results suggest that VEGFR-1 regulates subventricular NPC proliferation via a paracrine mechanism that is likely to be mediated by VEGF-A and VEGFR-2 signaling.

In the HC VEGFR-2 phosphorylation was only barely detectable in mice of either genotype and not induced after VEGF-A infusion, which is consistent with the absence of a proliferation effect on hippocampal NPCs in Flt-1TK ${ }^{-1-}$ mice. Previous studies, including our own, have shown that exogenous VEGF-A affects hippocampal neurogenesis in rats (Jin et al., 2002; Schänzer et al., 2004). Because the dose of VEGF-A is critical (Meng et al., 2006), the changes in VEGF-A protein in the HC of Flt-1TK ${ }^{-/-}$mice might not be sufficient to induce a measurable effect. Additional studies are needed to 
determine the diversity of VEGF-A actions on individual NPC populations.

Our results reveal that VEGFR1 signaling deficiency supports the migration of NPCs. In cultured Flt-1TK ${ }^{-1-}$ SVZ explants, neural cells migrated faster than WT cells. In vivo Flt-1TK ${ }^{-/-}$mice showed a vast decrease of $\mathrm{BrdU}^{+}$NPCs in the RMS compared with WT mice $6 \mathrm{~d}$ after BrdU injections. Concomitantly, in Flt-1TK ${ }^{-/-}$ mice, a significantly lower number of $\mathrm{BrdU}^{+}$cells left the RMS toward the CC and significantly more BrdU-labeled cells had already arrived in the PL of the OB than in WT mice. Altogether, this implies that VEGFR-1 regulates the migration speed and route of NPCs.

Intracerebroventricular infusion of VEGF-A in WT mice was sufficient to induce a migration phenotype identical to Flt-1TK ${ }^{-/-}$mice, clearly demonstrating that higher concentrations of cerebral VEGF-A protein are responsible for the changes in NPC migration. This is consistent with a recent report that demonstrates that, in cocultures, hypoxia-induced astrocytic VEGF-A secretion enhanced NPC migration (Xu et al., 2007). In a stroke model, overexpression of neuronal VEGF-A leads toward higher recruitment of cells into the lesion (Wang et al., 2007). However, the rate of cells recruited to the infarct was not separately assayed. In vitro VEGF-A affects NPC migration via VEGFR-2 (Zhang et al., 2003; Balenci et al., 2007). Our data reveal that also in vivo VEGFR-2 is phosphorylated in $\mathrm{DCX}^{+}$ NPCs located in the RMS and SVZ and that the augmented migration in Flt$1 T K^{-1-}$ is accompanied by increased VEGFR-2 activation throughout the RMS. Additional phosphorylation of p38MAPK, which is involved in actin reorganization, was decreased in forebrains of Flt-1TK ${ }^{-/-}$mice. This is in conformity with current studies reporting that p38MAPK signaling is opposing VEGFR-2-mediated effects of VEGF-A on neuroblastoma and endothelial cells (Yilmaz et al., 2003; Gomes and Rockwell, 2008).

Interestingly, phosphorylation of VEGFR-2 was only present in NPCs migrating within the RMS. Although in the RMS NPCs migrate in a chain migration mode, once they reach the $\mathrm{OB}$, they detach and migrate as single cells to their final location. Most cells stay in the GCL, but a smaller quantity migrates to the PGL, in which a small proportion obtains a dopaminergic interneuron subtype (Petreanu and Alvarez-Buylla, 2002; Winner et al., 2002). When entering the GCL, NPCs seem to lose phosphorylation of VEGFR-2, which hints toward an inactivation of the receptor in NPCs after their detachment from the migratory chains in the RMS. It would be appealing to explore which signals contribute to this transition.

In Flt-1TK ${ }^{-1-}$ mice, the increased proliferation in the SVZ and fewer cells leaving toward the $C C$ resulted in a higher number of new neurons in the outer layers of the OB. In accordance, the $\mathrm{PL}$ and PGL were enlarged in Flt-1TK ${ }^{-/-}$mice. Interestingly, in
Flt-1TK ${ }^{-/-}$mice, dopaminergic interneuron differentiation was enhanced.

We showed previously that administration of VEGF-A in rats leads to more OB interneurons (Schänzer et al., 2004). In the present study, we demonstrate that factors of the VEGF/VEGFR system affect in particular the differentiation of the dopaminergic olfactory interneurons in vivo. Current investigations are underway to determine whether this mechanism of VEGF-A regulation is also important in other dopaminergic systems. Other studies support this hypothesis that VEGF-A promotes dopaminergic cell differentiation. VEGF-A stimulates dopaminergic neuron development in vitro in prenatal rat mesencephalic explants (Silverman et al., 1999). VEGF-A application during the formation of embryoid bodies from human embryonic stem cells promotes the generation of neuroectodermal cells, which are differentiating mainly into neurons retaining a dopaminergic phenotype (Kim et al., 2006). Mice lacking hypoxia-inducible factor-1, which have lower VEGF-A levels in the brain, develop fewer dopaminergic neurons (Milosevic et al., 2007).

How VEGFR-1 signaling modulates VEGF-A protein levels in the adult brain remains to be determined. In the adult mouse brain, VEGF-A is expressed in glial cells of the neurogenic regions (Balenci et al., 2007) and by the choroid plexus. The increase in 
VEGF-A protein in Flt-1TK ${ }^{-1-}$ mice could result from reduced degradation of VEGF-A, because internalization and degradation of the receptor-ligand complex is dependent on the intracellular domain (Kobayashi et al., 2004; Mukherjee et al., 2006). Therefore, the truncated VEGFR-1 in Flt-1TK ${ }^{-/}$mice cannot be internalized, and, when all VEGFR-1 is bound, free VEGF-A might accumulate in the tissue (Mukherjee et al., 2006).

In summary, our study provides additional insights in the molecular control of adult neurogenesis. We show that VEGFR-1, originally known for its effects within the vascular system, is a negative regulator of adult olfactory neurogenesis. Interference with VEGFR-1 signaling in vivo altered VEGF-A concentration and led to a region-specific activation of VEGFR-2 in NPCs, thereby influencing neurogenesis without pronounced vascular abnormalities. This adds a new example of overlapping effects of growth factors that affect both the nervous and vascular systems.

\section{References}

Altman J, Das GD (1965) Autoradiographic and histological evidence of postnatal hippocampal neurogenesis in rats. J Comp Neurol 124:319-335.

Balenci L, Saoudi Y, Grunwald D, Deloulme JC, Bouron A, Bernards A, Baudier J (2007) IQGAP1 regulates adult neural progenitors in vivo and vascular endothelial growth factor-triggered neural progenitor migration in vitro. J Neurosci 27:4716-4724.

Beck H, Acker T, Püschel AW, Fujisawa H, Carmeliet P, Plate KH (2002) Cell type-specific expression of neuropilins in an MCA-occlusion model in mice suggests a potential role in post-ischemic brain remodeling. J Neuropathol Exp Neurol 61:339-350.

Bovetti S, Hsieh YC, Bovolin P, Perroteau I, Kazunori T, Puche AC (2007) Blood vessels form a scaffold for neuroblast migration in the adult olfactory bulb. J Neurosci 27:5976-5980.

Breier G, Clauss M, Risau W (1995) Coordinate expression of vascular endothelial growth factor receptor-1 (flt-1) and its ligand suggests a paracrine regulation of murine vascular development. Dev Dyn 204:228 -239.

Cameron HA, McKay RD (2001) Adult neurogenesis produces a large pool of new granule cells in the dentate gyrus. J Comp Neurol 435:406-417.

Cameron HA, Woolley CS, McEwen BS, Gould E (1993) Differentiation of newly born neurons and glia in the dentate gyrus of the adult rat. Neuroscience 56:337-344.

Cao L, Jiao X, Zuzga DS, Liu Y, Fong DM, Young D, During MJ (2004) VEGF links hippocampal activity with neurogenesis, learning and memory. Nat Genet 36:827-835.

Carlén M, Cassidy RM, Brismar H, Smith GA, Enquist LW, Frisén J (2002) Functional integration of adult-born neurons. Curr Biol 12:606-608.

Carmeliet P (2003) Blood vessels and nerves: common signals, pathways and diseases. Nat Rev Genet 4:710-720.

Carmeliet P, Ferreira V, Breier G, Pollefeyt S, Kieckens L, Gertsenstein M, Fahrig M, Vandenhoeck A, Harpal K, Eberhardt C, Declercq C, Pawling J, Moons L, Collen D, Risau W, Nagy A (1996) Abnormal blood vessel development and lethality in embryos lacking a single VEGF allele. Nature 380:435-439.

de Vries C, Escobedo JA, Ueno H, Houck K, Ferrara N, Williams LT (1992) The fms-like tyrosine kinase, a receptor for vascular endothelial growth factor. Science 255:989-991.

Eichmann A, Le Noble F, Autiero M, Carmeliet P (2005) Guidance of vascular and neural network formation. Curr Opin Neurobiol 15:108-115.

Ferrara N, Carver-Moore K, Chen H, Dowd M, Lu L, O'Shea KS, PowellBraxton L, Hillan KJ, Moore MW (1996) Heterozygous embryonic lethality induced by targeted inactivation of the VEGF gene. Nature 380:439-442.

Gomes E, Rockwell P (2008) p38 MAPK as a negative regulator of VEGF/ VEGFR2 signaling pathway in serum deprived human SK-N-SH neuroblastoma cells. Neurosci Lett 431:95-100.

Hashimoto T, Zhang XM, Chen BY, Yang XJ (2006) VEGF activates divergent intracellular signaling components to regulate retinal progenitor cell proliferation and neuronal differentiation. Development 133:2201-2210.

Hiratsuka S, Minowa O, Kuno J, Noda T, Shibuya M (1998) Flt-1 lacking the tyrosine kinase domain is sufficient for normal development and angiogenesis in mice. Proc Natl Acad Sci U S A 95:9349-9354.

Jin K, Zhu Y, Sun Y, Mao XO, Xie L, Greenberg DA (2002) Vascular endothelial growth factor (VEGF) stimulates neurogenesis in vitro and in vivo. Proc Natl Acad Sci U S A 99:11946-11950.

Kanno S, Oda N, Abe M, Terai Y, Ito M, Shitara K, Tabayashi K, Shibuya M, Sato Y (2000) Roles of two VEGF receptors, Flt-1 and KDR, in the signal transduction of VEGF effects in human vascular endothelial cells. Oncogene 19:2138-2146.

Kim BK, Kim SE, Shim JH, Woo DH, Gil JE, Kim SK, Kim JH (2006) Neurogenic effect of vascular endothelial growth factor during germ layer formation of human embryonic stem cells. FEBS Lett 580:5869-5874.

Kobayashi S, Sawano A, Nojima Y, Shibuya M, Maru Y (2004) The c-Cbl/ CD2AP complex regulates VEGF-induced endocytosis and degradation of Flt-1 (VEGFR-1). FASEB J 18:929-931.

Kuhn HG, Winkler J, Kempermann G, Thal LJ, Gage FH (1997) Epidermal growth factor and fibroblast growth factor- 2 have different effects on neural progenitors in the adult rat brain. J Neurosci 17:5820-5829.

Lendahl U, Zimmerman LB, McKay RD (1990) CNS stem cells express a new class of intermediate filament protein. Cell 60:585-595.

Levison SW, Goldman JE (1993) Both oligodendrocytes and astrocytes develop from progenitors in the subventricular zone of postnatal rat forebrain. Neuron 10:201-212.

Luskin MB (1993) Restricted proliferation and migration of postnatally generated neurons derived from the forebrain subventricular zone. Neuron 11:173-189.

Ma DK, Ming GL, Song H (2005) Glial influences on neural stem cell development: cellular niches for adult neurogenesis. Curr Opin Neurobiol 15:514-520.

Machein MR, Plate KH (2004) Role of VEGF in developmental angiogenesis and in tumor angiogenesis in the brain. Cancer Treat Res 117:191-218.

Makinen T, Olofsson B, Karpanen T, Hellman U, Soker S, Klagsbrun M, Eriksson U, Alitalo K (1999) Differential binding of vascular endothelial growth factor B splice and proteolytic isoforms to neuropilin-1. J Biol Chem 274:21217-21222.

Meng H, Zhang Z, Zhang R, Liu X, Wang L, Robin AM, Chopp M (2006) Biphasic effects of exogenous VEGF on VEGF expression of adult neural progenitors. Neurosci Lett 393:97-101.

Milosevic J, Maisel M, Wegner F, Leuchtenberger J, Wenger RH, Gerlach M, Storch A, Schwarz J (2007) Lack of hypoxia-inducible factor- $1 \alpha$ impairs midbrain neural precursor cells involving vascular endothelial growth factor signaling. J Neurosci 27:412-421.

Mukherjee S, Tessema M, Wandinger-Ness A (2006) Vesicular trafficking of tyrosine kinase receptors and associated proteins in the regulation of signaling and vascular function. Circ Res 98:743-756.

Olofsson B, Korpelainen E, Pepper MS, Mandriota SJ, Aase K, Kumar V, Gunji Y, Jeltsch MM, Shibuya M, Alitalo K, Eriksson U (1998) Vascular endothelial growth factor B (VEGF-B) binds to VEGF receptor-1 and regulates plasminogen activator activity in endothelial cells. Proc Natl Acad Sci U S A 95:11709-11714.

Petreanu L, Alvarez-Buylla A (2002) Maturation and death of adult-born olfactory bulb granule neurons: role of olfaction. J Neurosci 22:6106-6113.

Raab S, Plate KH (2007) Different networks, common growth factors: shared growth factors and receptors of the vascular and the nervous system. Acta Neuropathol 113:607-626.

Schänzer A, Wachs FP, Wilhelm D, Acker T, Cooper-Kuhn C, Beck H, Winkler J, Aigner L, Plate KH, Kuhn HG (2004) Direct stimulation of adult neural stem cells in vitro and neurogenesis in vivo by vascular endothelial growth factor. Brain Pathol 14:237-248.

Shen Q, Wang Y, Kokovay E, Lin G, Chuang SM, Goderie SK, Roysam B, Temple S (2008) Adult SVZ stem cells lie in a vascular niche: a quantitative analysis of niche cell-cell interactions. Cell Stem Cell 3:289-300.

Shibuya M, Yamaguchi S, Yamane A, Ikeda T, Tojo A, Matsushime H, Sato M (1990) Nucleotide sequence and expression of a novel human receptortype tyrosine kinase gene (flt) closely related to the fms family. Oncogene 5:519-524.

Silverman WF, Krum JM, Mani N, Rosenstein JM (1999) Vascular, glial and neuronal effects of vascular endothelial growth factor in mesencephalic explant cultures. Neuroscience 90:1529-1541.

Sun Y, Jin K, Childs JT, Xie L, Mao XO, Greenberg DA (2004) Increased severity of cerebral ischemic injury in vascular endothelial growth factorB-deficient mice. J Cereb Blood Flow Metab 24:1146-1152. 
Sun Y, Jin K, Childs JT, Xie L, Mao XO, Greenberg DA (2006) Vascular endothelial growth factor-B (VEGFB) stimulates neurogenesis: evidence from knockout mice and growth factor administration. Dev Biol 289:329-335.

Takahashi H, Shibuya M (2005) The vascular endothelial growth factor (VEGF)/VEGF receptor system and its role under physiological and pathological conditions. Clin Sci (Lond) 109:227-241.

Tavazoie M, Van der Veken L, Silva-Vargas V, Louissaint M, Colonna L, Zaidi B, Garcia-Verdugo JM, Doetsch F (2008) A specialized vascular niche for adult neural stem cells. Cell Stem Cell 3:279-288.

Terman BI, Carrion ME, Kovacs E, Rasmussen BA, Eddy RL, Shows TB (1991) Identification of a new endothelial cell growth factor receptor tyrosine kinase. Oncogene 6:1677-1683.

Wang Y, Jin K, Mao XO, Xie L, Banwait S, Marti HH, Greenberg DA (2007) VEGF-overexpressing transgenic mice show enhanced post-ischemic neurogenesis and neuromigration. J Neurosci Res 85:740-747.
Winner B, Cooper-Kuhn CM, Aigner R, Winkler J, Kuhn HG (2002) Longterm survival and cell death of newly generated neurons in the adult rat olfactory bulb. Eur J Neurosci 16:1681-1689.

Xu Q, Wang S, Jiang X, Zhao Y, Gao M, Zhang Y, Wang X, Tano K, Kanehara M, Zhang W, Ishida T (2007) Hypoxia-induced astrocytes promote the migration of neural progenitor cells via vascular endothelial factor, stem cell factor, stromal-derived factor-1alpha and monocyte chemoattractant protein-1 upregulation in vitro. Clin Exp Pharmacol Physiol 34:624-631.

Yilmaz A, Kliche S, Mayr-Beyrle U, Fellbrich G, Waltenberger J (2003) p38 MAPK inhibition is critically involved in VEGFR-2-mediated endothelial cell survival. Biochem Biophys Res Commun 306:730-736.

Zacchigna S, Lambrechts D, Carmeliet P (2008) Neurovascular signalling defects in neurodegeneration. Nat Rev Neurosci 9:169-181.

Zhang H, Vutskits L, Pepper MS, Kiss JZ (2003) VEGF is a chemoattractant for FGF-2-stimulated neural progenitors. J Cell Biol 163:1375-1384. 